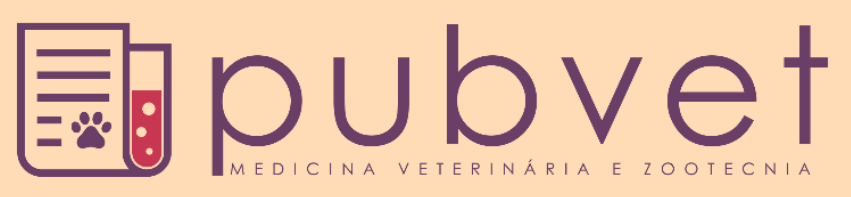

https://doi.org/10.31533/pubvet.v15n10a941.1-8

\title{
Neoplasmas do sistema urinário em cães e gatos
}

\author{
Priscila Inês Ferreira ${ }^{1 *} \bullet \mathbb{D}$, Milena Carolina Paz $^{2}$, Thais Francine Tumelero Lotis ${ }^{2}$, Guilherme \\ Rech Cassanego $^{3} \odot$ (D), Marcelo Rodrigues Ilha ${ }^{1}$, Saulo Tadeu Lemos Pinto Filho ${ }^{4}$ (D)
}

${ }^{1}$ Médico Veterinário Autônomo.

${ }^{2}$ Curso de graduação em Medicina Veterinária na Universidade Federal de Santa Maria.

${ }^{3}$ Programa de Pós-Graduação e Pesquisa em Medicina Veterinária na Universidade Federal de Santa Maria.

${ }^{4}$ Professor da Universidade Federal de Santa Maria, Departamento de Pequenos Animais, Santa Maria-RS, Brasil.

*Autor para correspondência, E-mail: priscila.inesf@gmail.com

Resumo. Neoplasmas primários do sistema urinário são incomuns em cães e gatos. Quando acometem os rins, o carcinoma é o mais comum nos cães e o linfoma nos gatos. Neoplasmas ureterais primários são raros nos cães e não existe relatos em gatos. O principal neoplasma vesical primário descrito em cães e gatos é o carcinoma de células de transição; porém, é mais frequente em cães. Neoplasmas uretrais ocorrem raramente e quando diagnosticados normalmente são amplificações de neoplasmas prostáticos ou de vesícula urinária. Com a finalidade de auxiliar no diagnóstico e na conduta médica para as duas espécies, esse trabalho tem o objetivo de apresentar uma revisão de literatura com os principais neoplasmas de ocorrência no sistema urinário que afetam cães e gatos. Apesar destas alterações serem infrequentes na rotina veterinária, é necessário um diagnóstico precoce para melhor prognóstico dos pacientes.

Palavras-chave: Caninos, felinos, neoplasmas

\section{Neoplasms of the urinary system in dogs and cats}

Abstract. Primary neoplasms of the urinary system are uncommon in dogs and cats. When affecting the kidneys, carcinoma appear like most common in dogs and lymphoma in cats. Primary ureteral neoplasms are rare in dogs and there aren't reports in cats. The primary bladder neoplasm described in dogs and cats is transition cell carcinoma; however, it is more frequent in dogs. Urethral neoplasms occur rarely and when diagnosed are usually amplifications of prostatic neoplasms or urinary bladder. The aim of assist in the diagnosis and medical conduct for both species, this report aims to present a literature review with the main neoplasms occurring in the urinary system that affect dogs and cats. Although these disorders are infrequent in the veterinary routine, an early diagnosis is necessary for a better prognosis for patients.

Keywords: Canines, felines, neoplasms

\section{Neoplasias del sistema urinario en perros y gatos}

Resumen. Las neoplasias primarias del sistema urinario son poco frecuentes en perros y gatos. Cuando afecta a los riñones, el carcinoma es el más común en perros y el linfoma en gatos. Las neoplasias ureterales primarias son raras en perros y no hay informes en gatos. La principal neoplasia primaria de vejiga descrita en perros y gatos es el carcinoma de células de transición; sin embargo, es más frecuente en perros. Las neoplasias uretrales ocurren raramente y cuando se diagnostican suelen ser amplificaciones de neoplasias prostáticas o de vejiga urinaria. Con el fin de ayudar en el diagnóstico y la conducta médica de ambas especies, este trabajo tiene como objetivo presentar una revisión de la literatura 
con las principales neoplasias que ocurren en el sistema urinario que afectan a perros y gatos. Aunque estos cambios son infrecuentes en la rutina veterinaria, es necesario un diagnóstico precoz para un mejor pronóstico de los pacientes.

Palabras clave: Caninos, gatos, neoplasias

\section{Introdução}

Em cães, tumores primários do sistema urinário são incomuns (Inkelmann et al., 2011). Aproximadamente $85 \%$ dos tumores renais são malignos, sendo nos cães o carcinoma o mais comum e nos gatos o linfoma, do qual pode ser primário ou metastático. Em cães, neoplasmas na vesícula urinária é o local de maior ocorrência dentre os do sistema urinário, enquanto que nos gatos é o neoplasma renal (Dourado et al., 2021; Little, 2016; MacPhail, 2013).

Neoplasmas renais costumam ser metástases, oriundos das vias hematógenas, linfática ou por invasão tumoral. Já os neoplasmas vesicais primários descritos são principalmente carcinoma de células de transição, ocorrendo 75-90\% dos tumores epiteliais nesse órgão. Neoplasmas ureterais primários são raros. Neoplasmas uretrais também ocorrem raramente, sendo os tumores nessa localização de origem vesical ou prostática (Daleck et al., 2016; Inkelmann et al., 2011; Little, 2016; MacPhail, 2013).

O diagnóstico de neoplasmas localizados no sistema urinário é realizado a partir da história clínica do paciente, exame clínico e físico, hematologia, bioquímica sérica, ultrassonografia, radiografia simples, radiografia contrastada, urografia excretora, tomografia, citologia aspirativa por agulha fina; porém, o diagnóstico definitivo é realizado apenas a partir de uma avaliação histopatológica (Braz et al., 2015; Daleck et al., 2016; Fighera, 2002; Little, 2016; Muniz et al., 2017).

Com a finalidade de auxiliar no diagnóstico e na conduta médica para as duas espécies, esse trabalho tem o objetivo de apresentar uma revisão de literatura com os principais neoplasmas de ocorrência no sistema urinário que afetam cães e gatos. Apesar destas alterações serem infrequentes na rotina veterinária, é necessário um diagnóstico precoce para melhor prognóstico dos pacientes.

\section{Neoplasmas renais}

Os neoplasmas renais primários comumente são malignos e o comportamento é muito variado. De modo geral, são unilaterais, mas o acometimento bilateral pode ocorrer, em especial, nos casos de síndromes neoplásicas sistêmicas (Dourado et al., 2021). Ademais, os tumores renais têm quatro origens distintas, das quais são tubular renal, células de transição, nefroblásticos e não epiteliais (MacPhail, 2014). O carcinoma renal canino, formado a partir da proliferação desordenada de células do epitélio tubular (Daleck et al., 2016), embora raro, é o tumor renal primário mais comum que acomete os cães (Dourado et al., 2021).

Em felinos, o linfoma aparece como o neoplasma renal primário mais frequente. Contudo, neoplasmas sem origem hemolinfática são raros, como carcinoma e nefroblastoma, e tumores mesenquimatosos (hemangiossarcoma, fibrossarcoma, condrossarcoma e liomiossarcoma). Devido ao grande suprimento sanguíneo, tumores metastáticos são comuns nesse órgão. Além dos neoplasmas renais citados em felinos, a literatura recente inclui um caso de cistoadenoma renal, um com carcinoma de células de transição formando um cisto perirenal, e dois com policitemia induzida por adenocarcinoma renal (Little, 2016). Troia et al. (2017) relataram um novo caso de policitemia associada ao adenocarcinoma renal em gato.

\section{Carcinoma de células renais}

O carcinoma de células renais (CCR) é o principal neoplasma renal encontrado em cães (Costa Neto et al., 2012), mas há também relatos em gatos (Daleck et al., 2016). A origem costuma ser primária e os cães afetados costumam ser de meia idade ou idosos. O padrão histológico mais encontrado é o tubular, mas também podem ser classificados em papilífero, sólido ou combinação de dois padrões (Inkelmann et al., 2011). No exame físico, pela palpação, pode-se notar aumento de volume em região anatômica renal, da qual associada à perda de peso, anorexia, hematúria, poliúria, desidratação, deve-se adicionar essa neoplasia entre os diagnósticos diferenciais (Bennett, 2004; Daleck et al., 2016). 
Cães com esse diagnóstico podem desenvolver sinais clínicos inespecíficos e duração crônica, como anorexia, depressão, perda de peso. No entanto, a falta de sinais clínicos evidentes podem acarretar no atraso do diagnóstico até o final do curso clínico da doença, momento em que já ocorreu metástase $\mathrm{O}$ tratamento desse neoplasma é cirúrgico, do qual deve-se avaliar o rim contralateral e verificar a funcionalidade, para então optar em nefrectomia do rim afetado e exérese das estruturas adjacentes acometidas pelo tumor (Daleck et al., 2016). Contudo, em casos de CCR altamente agressivo ou invasivo, opta-se pela quimioterapia citotóxica como terapia adjuvante à cirurgia (Bennett, 2004). Autores relatam uma sobrevida de quatro meses a um ano após o procedimento cirúrgico e ainda uma porcentagem de 69\% de metástase pulmonar (Daleck et al., 2016; Dourado et al., 2021). Outros autores revelam que cães com CCR eventualmente vivem por cinco anos após a remoção do rim afetado (MacPhail, 2014).

\section{Cistadenocarcinoma renal}

O cistadenocarcinoma renal é uma variante do carcinoma renal, do qual tem sido descrito principalmente em cães da raça Pastor Alemão como uma síndrome hereditária autossômica dominante (Inkelmann et al., 2011), causada por mutação do gene foliculina (FLCN), no locus Birt-Hogg-Dubé localizado no cromossomo cinco. Acomete animais de idade média de oito anos. Pode ser uni ou bilateral e ocorre juntamente à múltiplos nódulos fibrosos cutâneos e subcutâneos. No caso de cadelas, leiomiomas uterinos podem estar envolvidos na síndrome (Teixeira et al., 2006). Em gatos, há apenas um relato de cistadenoma renal, sendo esse a apresentação benigna do cistadenocarcinoma renal, mas esse segundo sem relatos de ocorrência em gatos (Little, 2016; Mosenco et al., 2008).

Duas hipóteses sugerem o surgimento de fibroadenomas cutâneos em pastores alemães: a primeira é que a dermatofibrose nodular seja uma síndrome paraneoplásica do cistadenocarcinoma renal; e a segunda sugere que sejam doenças independentes, mas ligadas ao mecanismo hereditário em comum. Devido a isso, é recomendado que esses animais não sejam utilizados para fins reprodutivos (Teixeira et al., 2006). Os nódulos subcutâneos são bem delineados e não encapsulados, compostos de fibroblastos e colágeno. São mais frequentemente vistos nos membros, costas e cabeça. Os cistos renais são transparentes a marrom avermelhado e podem aparecer como primeiros sinais da síndrome (Meuten, 2016).

Não há tratamento específico para a doença, mas pode ser indicado a excisão cirúrgica dos nódulos cutâneos, nefrectomia unilateral de rins císticos benignos ou mais gravemente afetados pelo tumor ou a histerectomia para tumores uterinos em fêmeas. O tratamento dos nódulos cutâneos pode não ser necessário, dependendo da sua localização e gravidade. A quimioterapia com Paclitaxel tem sido recomendado para evitar a progressão dos múltiplos cistos renais. Contudo, o avanço da doença pode ser lento, mas com um diagnóstico tardio o prognóstico torna-se reservado ou desfavorável por se tratar de uma enfermidade sistêmica (Langohr et al., 2002).

\section{Linfoma renal}

O linfoma é um neoplasma maligno, da qual origina-se em órgãos linfóides, mas pode ocorrer em qualquer órgão pela contínua migração dos linfócitos pelos diferentes tecidos do organismo (Costa Neto et al., 2012). O linfoma renal em cães, ocorre em menor incidência quando comparado em gatos. Os sinais clínicos incluem poliúria, polidipsia, perda de peso, anorexia, depressão (Muniz et al., 2017), hematúria de origem renal, renomegalia e insuficiência renal quando o processo é bilateral (Fighera, 2002).

Felinos diagnosticados com o vírus da leucemia felina tem maior propensão ao desenvolvimento de linfoma de modo geral e o vírus da imunodeficiência felina pode aumentar ainda mais a incidência. A idade média em felinos é de onze anos de idade, mas pode acometer gatos de um a 16 anos. Entretanto, os casos de linfoma renal, primário ou metastáticos, em felinos representam cerca de 5\% de todos os linfomas, sendo a expectativa de vida de 7,5 anos de idade, geralmente costumam ser FeLV negativos e normalmente afeta ambos os rins (Muniz et al., 2017).

O diagnóstico é realizado a partir dos sinais clínicos, exame físico do qual pode-se palpar o abdome e notar aumento do tamanho renal, hematologia, bioquímica sérica, ultrassonografia, punção aspirativa 
por agulha fina guiada por ultrassom para análise citopatológica ou por biopsia renal (Fighera, 2002; Little, 2016; Muniz et al., 2017).

O estadiamento de câncer é recomendado para o planejamento do tratamento. De modo geral, o tratamento cirúrgico não é recomendado para casos de linfoma. Contudo, indica-se a quimioterapia e já foram descritos vários protocolos de indução e manutenção usando-se diversos agentes quimioterápicos, como por exemplo vincristina, ciclofosfamida, L-asparaginase, doxorrubicina, metotrexato e prednisolona (Little, 2016). Para outros autores, é indicado no tratamento a nefrectomia parcial ou total quando afetado apenas um rim, associado à quimioterapia e radioterapia (Costa Neto et al., 2012). O prognóstico de felinos com linfoma renal depende do estágio do tumor, da função renal existente, da responsividade à quimioterapia e do estado de retrovírus (Little, 2016).

\section{Neoplasmas ureterais}

Em grande parte, são amplificações ou metástases de tumores primários originados na pelve renal ou na vesícula urinária. Em cães tumores primários ureterais raramente são diagnosticados, e em felinos, não há relatos de casos. Até recentemente, apenas 16 casos de tumores ureterais foram documentados na literatura veterinária (MacPhail, 2014). Dentre os neoplasmas primários relatados cita-se o papiloma de célula de transição, carcinoma de célula de transição, liomioma, liomiossarcoma, fibropapiloma e o mastocitoma (Carvalho et al., 2016). Polit et al. (2020) relataram o segundo caso de hemangiossarcoma ureteral primário descrito em cães. Enquanto que Steffey et al. (2004) relataram o primeiro caso em canino de mastocitoma ureteral.

Os neoplasmas de ureter, na maioria, apresentam-se unilateralmente e, assim sendo, a obstrução gradativa ocasionada pelo tumor propicia o desenvolvimento de hidronefrose e megaureter. Os sinais clínicos costumam ser inespecíficos e a manifestação irá depender das características do neoplasma. Hematúria, lombalgia, febre e anorexia são manifestações clínicas. Já o aparecimento de disúria vai estar associado com a ocorrência simultânea de urólitos vesicais ou ureterais, tumor em região de trígono ou até mesmo infecção do trato urinário (Carvalho et al., 2016).

Em termos de diagnóstico, inicialmente é difícil a detecção pois a investigação inicia-se somente quando se tem manifestações de obstrução de ureter. As técnicas mais utilizadas para diagnóstico é a radiografia abdominal simples, em que se observa o tamanho dos rins, porém só a urografia excretora juntamente com a fase de uretrograma indica lesão no ureter. Pela técnica pode-se detectar irregularidades, estreitamentos ou oclusão do lúmen do ureter. A ultrassonografia indica presença de hidronefrose e hidroureter (Carvalho et al., 2016).

O tratamento preconizado para este tipo de neoplasma é a ureterectomia parcial, quando for limitada ao ureter ou nefroureterectomia quando o neoplasma afeta a pelve renal e ureter. Em um paciente canino relado por Hanika \& Rebar (1980), com diagnóstico de carcinoma de células transicionais ureteral invasivo, o tratamento instituído foi nefroureterectomia unilateral e após dez meses não houve qualquer sinal de recorrência; porém, admite-se que a recidiva pode ocorrer. Já no paciente canino diagnosticado com hemangiossarcoma ureteral primário, foi realizado uma nefroureterectomia unilateral e cistectomia parcial devido invasão na vesícula urinária (Polit et al., 2020). Enquanto que no canino com diagnóstico mastocitoma, o tratamento instituído foi uma ureteroneocistostomia, mas após cinco meses ocorreu o óbito do paciente devido a outros neoplasmas não relacionados com o tumor em questão e também sendo confirmado na necropsia que não houve recidiva do tumor ureteral (Steffey et al., 2004).

Devido à baixa incidência, pouco se sabe a respeito da terapia quimioterápica para tratamento de neoplasmas de pelve ou de ureter, porém, pode-se utilizar piroxicam e compostos platinados para casos de carcinoma de células de transição. O prognóstico para neoplasmas exclusivos de ureter é favorável; porém, para metástases e tumores agressivos, a resposta ao tratamento é ruim (Carvalho et al., 2016).

\section{Neoplasmas da vesícula urinária}

O neoplasma da vesícula urinária ocorre mais frequentemente do que os neoplasmas do restante do sistema urinário em cães. Diferentemente de gatos, em que o rim costuma ser mais acometido por neoplasmas. Da vesícula urinária, o tumor mais frequente tanto em cães como em gatos é o carcinoma de células de transição $(75 \%$ a $90 \%)$. Em cães outros tumores com menor frequência pode ser 
diagnosticados, sendo os malignos o carcinoma de células escamosas; adenocarcinoma, fibrossarcoma, leiomiossarcoma, neurofibrossarcoma, carcinoma indiferenciado, rabdomiossarcoma e hemangiossarcoma. Os fibromas, leiomiomas, hemangiomas, rabdomiomas, mixomas e neurofibromas são tumores vesicais benignos (Inkelmann et al., 2011; MacPhail, 2013). Já nos felinos, os outros tipos relatados com menor frequência são o carcinoma de células escamosas, adenocarcinoma, liomiossarcoma, hemangiossarcoma e linfoma (Little, 2016).

O carcinoma de células escamosas vesicular não possui diferenças histológicas dos frequentemente vistos em outros locais do corpo. Ocorre principalmente em cães velhos e acomete mais machos do que fêmeas. Já o mixossarcoma na vesícula urinária de um cão foi relatado pela primeira vez por Braz et al. (2015), em uma paciente fêmea de onze anos de idade e após 60 dias do diagnóstico foi realizado a eutanásia devido ao agravamento do caso. A maioria dos tumores da bexiga de felinos é maligna e localmente invasiva. A média de idade dos gatos com neoplasia do trato urinário inferior varia entre $9 \mathrm{e}$ 13 anos. Um estudo demonstrou um risco levemente aumentado em fêmeas castradas, duas vezes maior, e machos castrados, 2,5 vezes maior, do que em gatos inteiros (Little, 2016).

Nas duas espécies, as técnicas de imagem, como raio-x, ultrassonografia, tomografia e ressonância magnética auxiliam no diagnóstico de neoplasmas vesicais. Também pode ser realizada a cistografia com contraste positivo ou duplo contraste, mas bário e iodeto de sódio nunca devem ser utilizados em gatos. Contudo, o diagnóstico definitivo é realizado através do exame histopatológico através da biópsia do tumor, que podem ser coletadas por meio de aspirado percutâneo, cateterismo traumático, cistoscopia ou laparotomia (Carvalho et al., 2016; Little, 2016).

\section{Carcinoma de células de transição}

É um tumor maligno derivado do epitélio transicional do trato urinário, que pode ocorrer em qualquer lugar da pelve renal, uretra prostática a uretra distal e bexiga, sendo que seu local de mais frequente desenvolvimento é no trígono da vesícula urinária e se estende para o corpo vesical. Em relação a epidemiologia, aparecem em cães mais velhos, com idade média de nove a onze anos, sem evidência de predisposição sexual ou racial. Os sinais clínicos mais presentes são hematúria, polaquiúria, cistite e disúria. Em gatos, a idade de aparecimento varia de 6 a 18 anos de idade e os sinais clínicos são referentes ao trato urinário inferior (Barboza et al., 2015; Little, 2016; Meuten, 2016). Em um estudo envolvendo 25 gatos com carcinoma de células de transição, os machos castrados foram os mais comumente acometidos (Little, 2016).

A etiologia dos tumores vesicais é multifatorial em cães, mas pouco se sabe em felinos. Em caninos, a exposição prolongada ao triptofano pode gerar carcinógenos endógenos, como o ortominofenol, e sua exposição prolongada ao urotélio vesical pode levar ao desenvolvimento do tumor de células de transição. A urina dos felinos não apresenta ortominofenol, o que pode explicar a menor incidência do tumor nessa espécie (Barboza et al., 2015; Carvalho et al., 2016; Little, 2016).

Macroscopicamente, o tumor de células de transição é caracterizado por ser de base ampla com nódulos salientes ou como um espessamento difuso na parede da vesícula urinária. Com a expansão do neoplasma, pode ocorrer obstrução uretral que, consequentemente, leva a retenção urinária e obstrução do fluxo ureteral (Carvalho et al., 2016). Na avaliação da lâmina, o tumor de células de transição caracteriza-se pela presença de grandes células epiteliais múltiplas com morfologia celular e nuclear atípicas, presença de corpos de Melamed-Wolinska (grandes vacúolos citoplasmáticos) e invasão da parede da vesícula. Geralmente, o tumor é papilar e as células neoplásicas possuem citoplasma eosinofílico abundante, com núcleos grandes e imaturos e muitas mitoses (Meuten, 2016). Para conferir precisão diagnóstica, é possível realizar imunohistoquímica em casos de lesões uroteliais proliferativas e fornecer características particulares aos carcinomas papilares, com o uso dos imunomarcadores uroplaquina III (UPIII) e da citoqueratina 7 (CK7) (Carvalho et al., 2016).

A terapia varia de acordo com o tipo, localização e tamanho do tumor dentro da vesícula urinária. $\mathrm{O}$ tratamento cirúrgico é difícil porque o local mais comum para a ocorrência é o trígono vesical, mesmo que os ureteres possam ser seccionados implantados no ápice da bexiga após a cistectomia parcial, ocorrerá incontinência urinária quando o trígono for removido, assim como, pielonefrite (MacPhail, 2014). Quando se opta pelo tratamento quimioterápico as drogas utilizadas são cisplatina, carboplatina, 
doxorrubicina, mitoxantrona e vimblastina (Martins, 2016; Telles et al., 2016). Porém, os tumores de vesícula urinária geralmente não respondem bem à quimioterapia. $\mathrm{O}$ prognóstico é ruim já que as medidas terapêuticas são, na maioria das vezes, ineficientes (Carvalho et al., 2016). Além desses, o piroxicam tenha sido associado à melhora clínica em cães com carcinoma de células de transição, mas não existem dados sobre segurança e eficácia em gatos (Little, 2016). Em um relato de casos envolvendo cinco cães com carcinoma de células de transição da vesícula urinária, a cirurgia foi realizada em quatro cães e teve caráter paliativo. A terapia quimioterápica instituída em dois pacientes foi somente com piroxicam e nos outros três piroxicam associado à ciclofosfamida. Ocorreu metástase pulmonar em um cão e insuficiência renal no restante devido hidronefrose. A sobrevida desses cães variou entre 123 a 730 dias (Barboza et al., 2015).

No estudo envolvendo 25 gatos com carcinoma de células de transição da vesícula urinária, foram tentados diversos tratamentos, como cirurgia, quimioterapia (carboplatina, doxorrubicina, ciclofosfamida) e piroxicam. Contudo, o surgimento de metástase no momento do diagnóstico foi de $20 \%$. O tempo mediano de sobrevida, independentemente do tipo de tratamento, foi de 261 dias, e quase todas as mortes foram atribuídas a evolução do tumor (Little, 2016).

\section{Fibromas e fibrossarcomas}

Os fibromas e fibrossarcomas são tumores mesenquimais de vesícula urinária, benignos e malignos, respectivamente, mais comumente encontrados em cães. Podem surgir em diferentes pontos quando originados da parede da vesícula urinária. Os fibrossarcomas caracterizam-se por invadir as camadas da parede vesical e prolongar-se para o lúmen, além de possuírem potencial metastático. No entanto, a taxa de metástase geral de fibrossarcomas é pouco conhecida (Bartges \& Polzin, 2011).

É recomendado a realização do estadiamento completo do tumor antes de se iniciar o tratamento. O tratamento preconizado é a ressecção cirúrgica. A terapêutica com quimioterápicos será indicada apenas para pacientes em estágio avançado, como tratamento paliativo e pode-se utilizar a doxorrubicina. Cães com tumores benignos apresentam prognóstico excelente, no entanto, o prognóstico para fibrossarcomas é desconhecido em razão dos poucos casos relatados (Bartges \& Polzin, 2011). Em um relato apresentado por Gonzales et al. (2016), de um canino, três anos de idade, com fibrossarcoma na vesícula urinária, o tratamento realizado foi apenas a ressecção cirúrgica e durante a avaliação de três meses não houve recidiva ou complicações.

\section{Neoplasmas uretrais}

Tumores primários de uretra em cães são pouco relatados na literatura (Silva et al., 2005) e em gatos ainda mais raros (Little, 2016). Quando diagnosticados em cães e gatos, normalmente são amplificações de neoplasmas prostáticos ou de vesícula urinária. Tumores uretrais primários são pouco incidentes em cães e raros em gatos (MacPhail, 2014). Há mais relatos em fêmeas em comparação aos machos e apresentam o tumor em torno dos dez anos de idade (Carvalho et al., 2016). Dentre os tumores pode-se citar o carcinoma de células de transição como o principal tumor uretral em cães, seguido dos carcinoma de células escamosas e adenocarcinomas (Silva et al., 2005; MacPhail, 2014). Em gatos a maioria dos casos relatados também têm sido carcinoma de células de transição (Little, 2016).

Silva et al. (2011) relataram o caso de uma canina fêmea, 16 anos de idade, com obstrução parcial da uretra média, causada por um fibrossarcoma, que culminou em hidronefrose bilateral e doença renal crônica, sendo optado pela eutanásia após 25 dias do diagnóstico. Enquanto que Takagi et al. (2005) relataram o caso de um gato macho inteiro, 15 anos de idade, com carcinoma de células de transição uretral, do qual foi tratado com uretrectomia parcial e radioterapia que forneceram uma sobrevida de 386 dias.

As manifestações clínicas mais frequentes apresentadas nos cães e gatos com neoplasma uretral são disúria, polaquiúria e hematúria, quando em estágio inicial. Em estágios mais avançados pode ocorrer incontinência urinária dependendo do local e do tipo de tumor. Podem causar obstrução da uretra (Carvalho et al., 2016).

A vesícula urinária pode se apresentar distendida em casos de obstrução uretral e, portanto, perceptível ao exame físico. Tumores uretrais dificultam ou inviabilizam a sondagem transuretral. 
Diagnóstico pode ser feito por meio do histórico do paciente. A ultrassonografia abdominal pode contribuir para o diagnóstico, sendo o exame de escolha para aqueles animais em que não há a possibilidade de sondagem. Radiografias abdominais simples não são eficazes (Carvalho et al., 2016). É importante que se investigue a causa de obstrução, desde o toque retal ao raio-x contrastado, citologia esfoliativa do canal da uretral, citologia aspirativa por agulha fina guiada por ultrassom e biópsia por laparotomia (Silva et al., 2011; Little, 2016).

A terapia para neoplasmas de uretra compreende a excisão cirúrgica nos casos em que apenas a uretra distal estiver envolvida. Os tumores uretrais que envolvem o comprimento total da uretra e/ou o trígono vesical geralmente não são operáveis, mas a colocação de um stent de modo paliativo nos casos de obstrução pode ser eficaz (MacPhail, 2014). Esses tumores não são tidos como quimiossensíveis, mas a cisplatina pode estabilizar a patologia, inclusive, os mesmos protocolos quimioterápicos empregados em casos de carcinoma de células de transição em vesícula urinária de cães podem ser utilizados para a terapêutica de neoplasma uretral (Carvalho et al., 2016).

\section{Considerações finais}

Neoplasmas do sistema urinário são infrequentes nas duas espécies. Dos tumores renais, o mais frequente em cães é o carcinoma renal, enquanto que em gatos, é o linfoma renal. Existe ainda, uma condição específica, de origem hereditária, que afeta a raça pastor alemão, o cistoadenocarcinoma renal. Neoplasmas ureterais podem ser amplificações ou metástases de tumores primários originados na pelve renal ou na vesícula urinária e os tumores primários ureterais em cães são raros e sem relatos em felinos. O tumor mais frequente que acomete a vesícula urinária é o carcinoma de células de transição, que se origina das células epiteliais transicionais do trato urinário. Quanto aos de origem uretral, o mais frequente é o carcinoma de células transicionais, mas normalmente são amplificações de neoplasmas prostáticos ou de vesícula urinária. Apesar desses tumores serem infrequentes, procura-se realizar o rápido diagnóstico, a fim de instalar rapidamente um tratamento para boas chances prognósticas.

\section{Referências bibliográficas}

Barboza, D. V, Guim, T. N., Silva, C. C., \& Fernandes, C. G. (2015). Carcinoma de células transicionais da bexiga em cães: Relato de cinco casos. Revista de Educação Continuada Em Medicina Veterinária e Zootecnia Do CRMV-SP, 13(3), 93. https://doi.org/10.29327/congressouniritter.260930.

Bartges, J., \& Polzin, D. (2011). Nephrology and urology of small animals. John Wiley \& Sons. https://doi.org/10.1002/9781118785546.

Bennett, F. (2004). Unilateral renal cell carcinoma in a Labrador retriever. The Canadian Veterinary Journal, 45(10), 860-862.

Braz, P. H., Martins, A. M. Q., \& Souza, A. I. (2015). Dificuldades no diagnóstico de mixosarcoma de bexiga urinária em cão. Acta Veterinaria Brasilica, 9(2), 171-175.

Carvalho, M. B., Vasconcellos, A. L., \& Alves, M. A. M. K. (2016). Neoplasias do sistema urinário. In C R Daleck, A. B. De Narde, \& S. Rodaski (Eds.), Oncologia em cães e gatos (pp. 675-697). Roca, Brasil.

Costa Neto, J. M., Lima, A. S. E., Ribeiro, L. G. R., Damasceno, K. A., Teixeira, D. M., Cruz, D. L., Melo, S. M. B., \& Moreira, E. L. T. (2012). Linfoma primário renal em cão: relato de caso. Medicina Veterinária (UFRPE), 6(1), 11-17.

Daleck, Carlos Roberto, Fonseca, C. S., \& Canola, J. C. (2016). Oncologia em cães e gatos. Roca.

Dourado, B. S. M., Biaggi, A., Roque, B., Almeida, F. M., Shigeo, R., \& Medina, A. M. (2021). Carcinoma renal bem diferenciado, padrão papilar em cão: Relato de caso. PUBVET, 15(4), 1-5. https://doi.org/10.31533/pubvet.v15n04a788.1-5.

Fighera, A. R. (2002). Linfossarcoma em cães. Ciência Rural, 32(5), 895-899.

Gonzales, C. Q., Oliveira, A. P. L., Zanini, D. A., Calvo, P. Z. U., \& Ikehara, M. T. (2016). Cão jovem com fibrossarcoma em bexiga urinária: relato de caso. Nosso Clínico, 19(114), 16-20.

Hanika, C., \& Rebar, A. H. (1980). Ureteral transitional cell carcinoma in the dog. Veterinary Pathology, 17(5), 643-646. https://doi.org/10.1177/030098588001700517. 
Inkelmann, M. A., Kommers, G. D., Fighera, R. A., Irigoyen, L. F., Barros, C. S. L., Silveira, I. P., \& Trost, M. E. (2011). Neoplasmas do sistema urinário em 113 cães. Pesquisa Veterinária Brasileira, 31(11), 1102-1107.

Langohr, I. M., Irigoyen, L. F., Salles, M. W. S., Kommers, G. D., \& Barros, C. S. L. de. (2002). Cistadenocarcinoma renal e dermatofibrose nodular em cães Pastor Alemão: 4 casos. Ciência Rural, 32(4), 621-626. https://doi.org/10.1590/s0103-84782002000400012.

Little, S. E. (2016). O gato: medicina interna. Editora Roca.

MacPhail, C. M. (2013). Surgery of the bladder and urethra. In T. W. Fossum (Ed.), Small animal surgery (pp. 735-779). Elsevier.

MacPhail, C. M. (2014). Cirurgia dos sistemas reprodutivo e genital. In T. W. Fossum (Ed.), Cirurgia de pequenos animais. Elsevier.

Martins, A. R. C. (2016). Carcinoma de células de transição de bexiga em cães. In Faculdade de Medicina e Veterinária: Vol. Master of. Universidade de Trás-dos-Montes e Douro.

Meuten, D. J. (2016). Tumors in domestic animals. John Wiley \& Sons.

Mosenco, A. S., Culp, W. T. N., Johnson, V., French, A., \& Mehler, S. J. (2008). Renal cystadenoma in a domestic shorthair. Journal of Feline Medicine and Surgery, 10(1), 102-105. https://doi.org/10.1016/j.jfms.2007.07.001.

Muniz, I. M., Andrade, E. R., \& Voigt, P. R. (2017). Primary renal lymphoma in domestic cat (Felis catus): Case report. Veterinaria e Zootecnia, 24(1), 120-125.

Polit, J. A., Moore, E. V, \& Epperson, E. (2020). Primary Ureteral Hemangiosarcoma in a dog. BMC Veterinary Research, 16(1), 1-6. https://doi.org/10.1186/s12917-020-02609-8.

Silva, M. C., Fighera, R. A., Souza, T. M., Graça, D. L., \& Barros, C. S. L. (2005). Urethral adenocarcinoma in a bitch. Ciência Rural, 35(4), 935-937.

Silva, M. M. V, Crivelenti, L. Z., Momo, C., \& Honsho, D. K. (2011). Fibrossarcoma uretral primário em cadela. Arquivo Brasileiro de Medicina Veterinária e Zootecnia, 63, 1353-1358.

Steffey, M., Rassnick, K. M., Porter, B., \& Njaa, B. L. (2004). Ureteral mast cell tumor in a dog. Journal of the American Animal Hospital Association, 40(1), 82-85. https://doi.org/10.5326/0400082.

Takagi, S., Kadosawa, T., Ishiguro, T., Ohsaki, T., Okumura, M., \& Fujinaga, T. (2005). Urethral transitional cell carcinoma in a cat. Journal of Small Animal Practice, 46(10), 504-506. https://doi.org/10.1111/j.1748-5827.2005.tb00280.x.

Teixeira, L., Franco, P., Amorim, R., \& Amstalden, E. M. (2006). Diferenciação histopatológica e imunoistoquímica de leiomiomas e fibromas vaginais em cadelas. Boletim de Medicina Veterinária, 2(2), 3-14.

Telles, S. A., Monteiro, R. C. P., Corrêa, F. M., Calvo, P. Z. U., \& Oliveira, A. P. L. M. (2016). Carcinoma de células de transição de bexiga em cão: Relato de caso. PUBVET, 11(1), 82-86. https://doi.org/10.22256/pubvet.v11n1.82-86.

Troia, R., Agnoli, C., Fracassi, F., Bettini, G., Sfacteria, A., Pisoni, L., \& Dondi, F. (2017). Renal adenocarcinoma-associated erythrocytosis in a cat: clinicopathological features and immunohistochemical results. Open Veterinary Journal, 7(4), 294-299. https://doi.org/10.4314/ovj.v7i4.1.

Histórico do artigo:

Recebido: 24 de junho de 2021

Aprovado: 17 de jujho de 2021
Licenciamento: Este artigo é publicado na modalidade Acesso Aberto sob a licença Creative Commons Atribuição 4.0 (CC-BY 4.0), a qual permite uso irrestrito, distribuição, reprodução em qualquer meio, desde que o autor e a fonte sejam devidamente creditados. 